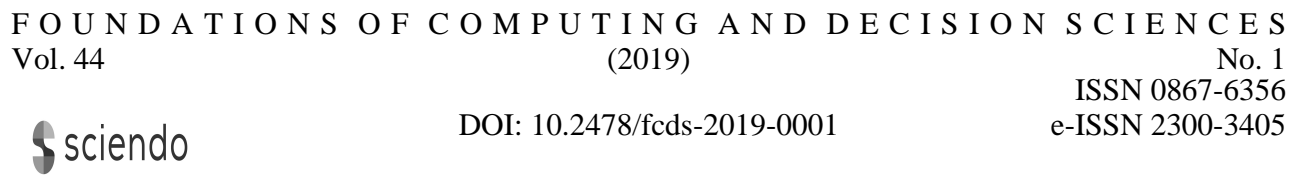

\title{
Preface to the Special Issue on Philosophy in Computer Science
}

\author{
Sławomir Leciejewski*
}

\begin{abstract}
Fleck's concept of thought style allows to realize the fact that in contemporary empirical sciences we deal with a computer thought style, as most research works are currently conducted with the use of computer-aided systems. In this article I support the thesis that contemporary research works are dominated by the computer research style. I refer to the findings of Fleck, Bolter, Castells, Crombie and Hacking.
\end{abstract}

Keywords: thought style, computer-aided research, computer research style.

Ludwik Fleck, a philosopher, microbiologist and immunologist, was one of the first to develop the concept of thought styles. He understood thought style as an applied in a certain environment approach to research, observation and experimentation, and the interpretation of the experimentation data. It is also a pattern of thinking and evaluation. The thought style is "directed perception along with the corresponding mental and material processing of what is perceived. It is characterized by common features of the problems that the collective is interested in; opinions that it considers obvious; methods it uses as cognitive means " [7].

For Fleck there are no such things as purely reporting statements, i.e. descriptions of bare facts. Every statement concerning facts is an interpretation in the light of the applied thought style, since "the fact must be expressed in the thought-collective style" [7]. Thanks to the common thought style, researchers in a given field come to corresponding observation results. In addition, a specific thought style is associated with certain problems. What in the light of one thought style deserves to be a serious problem, in the light of another may be considered as an apparent or trivial matter. In other words, each thought style is a result of social determinants. As long as it does not change, certain phenomena cannot be discerned,

* Adam Mickiewicz University in Poznań, Institute of Philosophy, ul. Szamarzewskiego 89c, 60-568 Poznań, slaaw@amu.edu.pl 
as a given thought style treats them as irrelevant, accidental, and therefore rejects or disregards them [7].

The link to a given scientific thought style is further reinforced by instruments used in laboratories that have been designed according to the rules of that very style. This style also implies certain treatment of the objects studied - it redirects the thinking to follow the path of a given style. It is worth pointing out that computers in general are used universally in the majority of scientific laboratories as universal instruments supporting scientific research.

The widespread use of computers, development of software and variety of peripherals has made it possible to perform more efficiently the functions of calculation, control, advisory, diagnostic, monitoring, measurement, control, and more. Such diverse and versatile applications of computer systems have enabled them to be used in almost all areas of human activity, starting from the scientific research. The most computerized elementary particle physics laboratory is currently CERN (fr. Conseil Européen pour la Recherche Nucléaire).

In 2012, the results of the search for Higgs boson in computer-aided experiments on the Large Hadron Collider (LHC) were presented at CERN. In the CMS (Compact Muon Solenoid) and ATLAS (A Toroidal LHC Apparatus) experiments, in a proton-proton collision analysis involving two photons or four leptons, a substantial signal was received that can be interpreted as the production and disintegration of particles at a mass of $125,3 \pm$ $0.4 \mathrm{GeV}$ (CMS) or $126 \pm 0.4 \mathrm{GeV}$ (ATLAS). The properties of this particle indicate that this is the sought-after Higgs boson (these results were published in a series of three comprehensive articles, a result of work of a few hundred scientists: [4, 13, 14]).

It is worth asking the question whether people working at CERN, at the ATLAS and CMS experiments, could obtain different results. If - which seems very likely - these two research groups belong to the same thought style, they must "perceive" almost the same thing, e.g. an elementary particle interpreted as Higgs boson, with the same energy within the limits of statistical errors $( \pm 0,4)$. It is worth noting that in the LHC the CMS and ATLAS experiments differ only in measuring devices. Other elements of this complex, computerized experimental system are the same or very similar, constructed in accordance with the common thought style applied by these groups. "One can even note that the more a domain of knowledge is or becomes developed, the less material the differences in opinions become" [7], which can easily be observed by analyzing contemporary particle physics experiments (e.g. LHC at CERN).

In the first half of the 1980s an American philosopher Jay David Bolter in his book Turing's Man (Bolter 1984) developed the thesis that the widespread use of computers must change our way of thinking about ourselves and the world, and consequently bring about a new image of the world and man. He came to his findings through his analyses of the history of philosophy. He showed that the great philosophical concepts of the world and man, beginning with Plato, through Descartes and Newton until the nineteenth century, were shaped by the prevailing technologies at that time. The ones that were then most philosophically inspiring were called "defining technologies". Now, according to Bolter, such technology is computer. It defines or redefines the role of man in terms of nature, speaking of man as "information processor" and nature as "information to be processed" [2]. 
It is noteworthy that, for example, modern biology is increasingly attempting to analyze organisms as living structures that serve to process and memorize information [11]. We also deal with a similar way of using the notion of information processing, which is most often used to define what information technology is all about, in physics and cosmology. It is becoming increasingly common to assume, after John Archibald Wheeler, that the physical world consists primarily of information, and that matter and energy are secondary. Michat Heller notes that it is convenient to talk about the Universe in terms of software and hardware. This fits, in his view, with the mathematical structure of the Universe that we discover and illustrates the relationship between mathematical and physical laws (software) and their existing effect - the Universe (hardware) [10].

Regardless of whether the above solutions are acceptable, they share a certain feature. All in all, the analogy with computers is a convenient way of illustrating how the Universe works. No wonder, Bolter would say, because for modern man it is the easiest to imagine the action of nature on a computer model. In addition, in the opinion of the author of Turing's Man, such a universally applicable style of solving various problems (also scientific ones) using a computer has an influence on the thought style of people of the computer age. They think that a significant portion of human intellectual activity can be outsourced to computers conducting increasingly complex computing processes [2]. This, according to Bolter, leads in the end to the profound transformation of the thought style of modern man. He claims that the current Western style of analysis will be transformed into modeling and simulations creating a new style of electronic problem solving [2].

It is easy to observe that computer simulations have a profound effect on the way many people think, and they almost always base their choices on the results of a variety of computer simulations (such as weather forecasts). Manuel Castells in his monumental work The Information Age argues in favor of a similar thesis on real virtuality. He argues that modern man practically no longer benefits from direct experience when it comes to the perception of the world. Everything reaches him through electronic digital media. The reality is what is displayed on TV or computer [3].

A question may be raised whether this type of real virtuality has also influenced scientists. Is the computer style of research currently predominant? Considering the abovementioned examples from the fields of biology, physics and cosmology, it seems impossible to resist the impression that researchers working in these fields are primarily thinking about computerbased ways of solving their research problems. It is, therefore, concluded that the concept of Fleck's thought style is sufficient to realize that in contemporary empirical science we are dealing with computer thought style. Fleck's thought style, as discussed above, is a standardized approach to research, observation and experimentation, and the interpretation of experimentation data. Nowadays most of these types of research procedures are carried out using computers, so it is reasonable to talk about a computer thought style that has been prevalent in science since the 1980s.

The concept of style, introduced by Ostwald Spengler (in 1918) [15] and Ludwik Fleck (in 1935), in a different sense, was subject to numerous further paraphrases, modifications and developments. Alistair C. Crombie also made a reference to it (in 1994) [6], by separating three constitutive elements of the style of scientific thinking: type of reasoning used (the 
methods of discovery and proof), the concept of nature (beliefs about what is in the world that can be discovered), mental habits (expectations and reactions to innovations and changes, and within them - social and individual tendencies).

The general characteristics of the scientific thought style presented here also support the thesis that in modern empirical science we are dealing with a computer style of scientific thinking. There are already preliminary studies of computer systems of scientific discovery [8], computers are able to carry out a lot of evidence and man cannot cope with them without the assistance of computers [1], it is becoming increasingly common to think about nature as a being which processes information [11]. In addition, most of the research is conducted using the assistance of computers, whether it is a collective or individual work. The mental habit of researchers working at the turn of the 20th and 21 st centuries is to obtain their results using the assistance of computer techniques. It is clear, therefore, that it is reasonable to talk about computer scientific style.

In his other publication, Crombie distinguishes six dominant styles of thought, research and scientific work in the Western scientific tradition [5]:

1. theoretical and mathematical postulates applied in modern mathematics,

2. use of experiment, both for the control of postulates and cognition through observation and measurement,

3. constructing hypothetical models - analogues,

4. organizing diversity through comparison and taxonomy,

5. use of statistical analysis and probability calculus,

6. historical derivation of nature development principles.

The style sequence given by Crombie corresponds to the historical order of their emergence in the history of Western science. According to Ian Hacking, Crombie's study was largely based only on the history of the development of the science of the West, from ancient times until the seventeenth century. He claims that only with the last style we reach the 19th century. Thus, he complements Crombie's list with the fundamental 17th century innovation - laboratory science, which is characterized by the construction of apparatus intended to isolate and purify the existing phenomena and to create new. Hacking also claims that some styles are more effective than others. For example, he perceived this laboratory style that he characterized as very effective as its main characteristic is the construction of apparatuses to produce new phenomena. He also claims that in science, where the dominant style of scientific inquiry is the laboratory style, the scientific apparatus should be the focus of the methodologists or philosophers of science, as it sets the standards of objectivity, determines the order of scientific work, and delineates new cognitive horizons [9].

Since the 1980s we have been dealing with computer-aided experimental research [12]. Some of it are laboratory tests in the Hacking's sense, which can also be computer aided. It is much easier and more precise to isolate and purify the existing phenomena and create new ones (for example, thanks to the LHC at CERN) if a part of the experimental system is a computer or multiple computers connected together. The computer style of experimental research would thus include a computer-aided model of laboratory research (i.e., augmented with a computer-aided version of a laboratory style), as not all experimental research serves to stabilize and create new phenomena. Even a broader category would be a computer style 
of scientific research that would include computer style of experimental research and other, however computer-aided, research styles distinguished by Crombie (e.g. computer-aided mathematical reasoning, computer-aided modeling, computer-aided taxonomy style and historical and genetic computer-aided statistical style).

By analyzing the contemporary work of scientists, it can be observed that almost all empirical research procedures (e.g. exploration, justification, explanation, classification, etc.) are computer aided. Computer can perform many different roles in empirical science. Key functions of computers in empirical sciences are [12]:

- obtaining empirical data from measuring devices by analogue-to-digital converters and interfaces, and controlling the course of the experiment by digital-to-analogue converters and actuators,

- collecting empirical data (creating digital empirical databases),

- comparing empirical and theoretical data,

- formulating simple phenomenological laws (computer induction generalizations formulated on the basis of digital empirical databases),

- numerical justification for conducting further experiments (optimization of subsequent experiments by narrowing the possible class of experiments),

- computer simulations of phenomena/processes (based on collected empirical data and assumed theories),

- design and optimization of new computer-aided experimental sets,

- visualization of empirical data and obtained results of numerical analysis,

- electronic communication between scientific centers (data exchange, simulation and visualization),

- optimization of man-machine communication processes (scientist-computer system supporting scientific research).

Therefore, we can indeed talk about the computer style of experimental research, and its extension is the computer style of scientific research. It is clear that nowadays all types of research listed within the six historical Crombie's thought styles can be accomplished by using a computer that is properly programmed and has appropriate peripherals. There are already - although still very imperfect - computer systems of scientific discoveries, thanks to which computers themselves can come to simple generalizations and formulate the laws of science [8].

Particularly characteristic of the computer style of scientific research are the two constitutive elements proposed by Crombie: the type of applied reasoning (methods of discovering and providing evidence) and mental habits. Their common denominator is the computer as a tool used in most discoveries, and as a tool for comparing empirical data with a variety of databases, e.g. representing the expected results derived from the adoption of a given theory. Studying a variety of objects and phenomena using a computer is also a characteristic mental habit of most people involved in modern research. Therefore, in the contemporary scientific research what dominates is the computer style of research, as most research works are carried out using computer-aided systems. 
This volume concerns the philosophical analysis of various research projects conducted with the use of computers. The authors of these publications undoubtedly remain in the circle of researchers carrying out their ponderings by relying on the computer style of scientific research. In the first work by Witold Marciszewski entitled „The progress of science from a computational point of view: the drive towards ever higher solvability" it was suggested that, in the progress of science an essential role is played by the feedback between intellectual intuitions (intuitive solvability) and algorithmic procedures (effective solvability).

In the publication by Pawel Stacewicz entitled „From Computer Science to the Informational Worldview. Philosophical Interpretations of Some Computer Science Concepts", the author defends the thesis that modern computer science has a significant philosophical potential, which is expressed in the form of a worldview, called informational worldview.

Another article by Paweł Polak and Roman Krzanowski entitled „Deanthropomorphized Pancomputationalism and the Concept of Computing" the authors claim that pancomputationalism is quite a wide-ranging concept, but most of its variants, either implicitly or explicitly, rely on Turing's conceptualizations of a computer and computing, which are obvious anthropomorphisms. This work questions the concept of pancomputationalism based on Turing computing and asks what concept of computation can be used to avoid the constrains of anthropomorphisations.

Further publication by Iwo Błądek, Maciej Komosiński and Konrad Miazga entitled „Mappism: formalizing classical and artificial life views on mind and consciousness” begins with a reflection that throughout centuries, philosophers have attempted to understand the disparity between the conscious experience and the material world - i.e., the problem of consciousness and the apparent mind-body dualism. In light of the advent of strong artificial intelligence and the development of increasingly complex artificial life models and simulations, we need a well-defined, formal theory of consciousness. In order to facilitate this, in this work the authors introduce mappism. Mappism is a framework in which alternative views on consciousness can be formally expressed in a uniform way, thus allowing one to analyze and compare existing theories and enforcing the use of explicit functions and variables in the language of mathematics. Using this framework, they describe classical and artificial life approaches to consciousness.

The main aim of the work by Paweł Lupkowski and Marta Gierszewska „Attitude Towards Humanoid Robots and the Uncanny Valley Hypothesis" was to check whether the well established measures concerning the attitude towards humanoid robots are good predictors for the uncanny valley effect. We present a study in which 12 computer rendered humanoid models were presented to our subjects. The study covered also the evaluation of the perceived robots' characteristic and the emotional response to them.

The last publication by Krzysztof Sołoducha entitled „Analysis of facial expression movements and the phenomenon of frontal asymmetry as the basis for automation of the research of hidden cognitive attitudes. Some basic remarks" shows how, using the achievements of modern computer science, psychology and neurobiology, we can search for an answer to the question about the a priori mechanisms of shaping a phenomenal image of reality given by experience. This phenomenalism statement is very close to the, so called, Bayesian model of mind by Karl Friesen. The result of the consideration is to be a 
neuromachine project whose task will be to automate and mass research of hidden cognitive attitudes.

\section{Acknowledgement}

This article is a translation of chapter 4.3 of [12] which was originally published in Polish. This version contains changes compared to the original one.

\section{References}

[1] Białynicki-Birula I., Białynicka-Birula I., Modeling Reality. How Computers Mirror Life, Oxford University Press, Oxford, 2004.

[2] Bolter J.D., Turing's Man. Western culture in the computer age, The University of North Carolina Press, Chapel Hill, 1984.

[3] Castells M., The Rise of the Network Society, The Information Age. Economy, Society, and Culture, Volume 1, Blackwell Publishing Ltd., Oxford, 2010.

[4] Combined search for the Standard Model Higgs boson using up to $4.9 \mathrm{fb}^{-1}$ of pp collision data at $\sqrt{s}_{s}=7 \mathrm{TeV}$ with the ATLAS detector at the LHC, ,Physics Letters B", 710, 2012, 49-66.

[5] Crombie A.C., Designed in the Mind: Western Visions of Science, Nature and Humankind, [in:] Science, Art and Nature in Medieval and Modern Thought, Hambledon Press, London, 1996, 1-12.

[6] Crombie A.C., Styles of Scientific Thinking in the European Tradition: The History of Argument and Explanation Especially in the Mathematical and Biomedical Sciences and Arts,: Gerald Duckworth \& Company, London, 1994.

[7] Fleck L., Powstanie i rozwój faktu naukowego: wprowadzenie do nauki o stylu myślowym i kolektywie myślowym, Wydawnictwo Lubelskie, Lublin, 1986.

[8] Giza P., Filozoficzne i metodologiczne aspekty komputerowych systemów odkryć naukowych,: Wydawnictwo UMCS, Lublin, 2006.

[9] Hacking I., Language, Truth and Reason, [in:] Rationality and Relativism, M. Hollis, S. Lukes (eds), MIT Press, Cambridge, 1982, 48-66.

[10] Heller M., Nauka jako odkrywanie sensu, Wydawnictwo Znak, Kraków, 2002.

[11] Korohoda W. (2005), Informacja w biologii, [in:] Informacja a rozumienie, M. Heller, J. Mączka (red.), PAU-OBI-Biblos, Kraków-Tarnów, 2005, 91-95.

[12] Leciejewski S., Cyfrowa rewolucja w badaniach eksperymentalnych. Studium metodologiczno-filozoficzne, Wydawnictwo Naukowe UAM, Poznań, 2013.

[13] Observation of a new boson at a mass of $125 \mathrm{GeV}$ with the CMS experiment at the LHC, „Physics Letters B”, 716, 2012, 30-61.

[14] Observation of a new particle in the search for the Standard Model Higgs boson with the ATLAS detector at the LHC, „Physics Letters B”, 716, 2012, 1-29.

[15] Spengler O., Zmierzch Zachodu. Zarys morfologii historii uniwersalnej, Wydawnictwo KR, Warszawa, 2001. 